\title{
Fungos conidiais do bioma Caatinga I. Novos registros para o continente americano, Neotrópico, América do Sul e Brasil
}

\author{
Conidial fungi from Caatinga biome I. New records for Americas, Neotropics, South America and Brazil
}

\author{
Davi Augusto Carneiro de Almeida ${ }^{1,2}$, Tasciano dos Santos Santa Izabel ${ }^{1}$ \\ \& Luís Fernando Pascholati Gusmão ${ }^{1}$
}

\begin{abstract}
Resumo
Durante inventário de fungos conidiais realizado na Serra da Fumaça, Pindobaçu, estado da Bahia, Brasil, foram identificadas 44 espécies. Destas, cinco representam novos registro para o continente americano: Dendryphiosphaera parvula Nawawi \& Kuthub., Diplococcium dendrocalami Goh, K.D. Hyde \& Umali, Sporidesmiella aspera Kuthub. \& Nawawi, S. fusiformis W.P. Wu e Triposporium verruculosum R.F. Castañeda, Gené \& Guarro. Stanjehughesia hormiscioides (Corda) Subram. é um novo registro para o Neotrópico; Hemibeltrania decorosa R.F. Castañeda \& W.B. Kendr constitui novo registro para a América do Sul e Spadicoides macroobovata Matsush. é um novo registro para o Brasil. Descrições, ilustrações, distribuição geográfica mundial e comentários são apresentados para os novos registros citados. Uma lista com as demais espécies encontradas é adicionada.

Palavras-chave: hifomicetos, serrapilheira, taxonomia.

Abstract

During inventory of conidial fungi at Serra da Fumaça, Pindobaçu, Bahia State, and Brazil, 44 species were found. Five species are new records for Americas: Dendryphiosphaera parvula Nawawi \& Kuthub., Diplococcium dendrocalami Goh, K.D Hyde \& Umali, Sporidesmiella aspera Kuthub. \& Nawawi, S fusiformis W.P. Wu, and Triposporium verruculosum RF Castañeda, Gené \& Guarro. Stanjehughesia hormiscioides (Corda) Subram. is a new record for Neotropics; Hemibeltrania decorosa RF Castañeda \& WB Kendr. is a new record for South America and Spadicoides macroobovata Matsush is a new record for Brazil. Descriptions, illustrations, geographical distribution and comments are presented for new records. A list of species founded is included too.
\end{abstract}

Key words: hyphomycetes, litter, taxonomy.

\section{Introdução}

A Caatingaé um bioma exclusivamente brasileiro e está totalmente incluido na região semi-árida. Ocupa uma área de 700.000 a $800.000 \mathrm{~km}^{2}$, o que corresponde a cerca de $10 \%$ do território brasileiro (Sampaio et al. 2002), abrangendo parte dos estados do Ceará, Rio Grande do Norte, Paraíba, Pernambuco, Piauí, Alagoas, Sergipe, Bahia e Minas Gerais (Prado 2003; Ministério da Integração Nacional 2005). Apesar disso, é o mais negligenciado, menos protegido e um dos mais ameaçados biomas brasileiros (Leal et al. 2003). Embora o aspecto fitofisionômico predominante da região semi-árida brasileira seja a caatinga, há a ocorrência de outros tipos vegetacionais como matas ciliares, matas estacionais, cerrados, tabuleiros e campos rupestres (Barbosa et al. 2008).
Investigações sobre fungos conidiais associados à serapilheira do bioma Caatinga tem revelado um número significativo desses microfungos (Gusmão et al. 2005; Gusmão \& Barbosa 2005; Cruz et al. 2007c; Barbosa et al. 2008; Marques et al. 2008; Barbosa et al. 2009a, b; Cruz \& Gusmão 2009a, b), com descoberta de várias novas espécies (Barbosa et al. 2007; Cruz et al. 2007a, b; Marques et al. 2007; Cruz et al. 2008; Gusmão et al. 2008a). Gusmão et al. (2006) apresentaram uma síntese do conhecimento sobre a diversidade de fungos na região semi-árida brasileira, sendo os fungos conidiais o grupo mais representativo com 407 das 955 espécies de fungos registrados para essa região, àquela época. Posteriormente, Gusmão et al . (2008b) atualizaram o número de fungos conidiais

\footnotetext{
${ }^{1}$ Universidade Estadual de Feira de Santana, Av. Transnordestina s/n, C.P. 252 e 294, 44036-900, Feira de Santana, BA, Brasil

${ }^{2}$ Autor para correspondência: daviaugusto@gmail.com
} 
para 437 espécies, distribuídas em 186 gêneros. Entretanto, esses dados ainda estão longe de refletir o quadro real da diversidade de fungos presentes nesse bioma.

O objetivo do presente trabalho foi realizar um levantamento e estudo taxonômico dos fungos associados à decomposição da serapilheira na Serra da Fumaça, incluindo a descrição, comentários, ilustração, e distribuição geográfica mundial das espécies encontradas.

\section{Material e Métodos}

As expedições de coleta foram realizadas em 2008, a cada dois meses, abrangendo o final do período seco (agosto e outubro) e início do periódo chuvoso (dezembro), na Serra da Fumaça, município de Pindobaçu (1074'S e 40³6'W), Bahia, Brasil. Essa serra compõe, junto com outras, uma cadeia de serras denominadas de Serra da Jacobina, a qual se estende por cerca de $200 \mathrm{~km}$ no sentido norte-sul, na porção norte do estado da Bahia, com 15-25 km de largura e altitude de até $1.300 \mathrm{~m}$ (Milesi et al. 2002; Mascarenhas et al. 1998). Foram coletadas amostras de serapilheira em área de campo rupestre e mata ciliar, sendo que nesta última também foram coletadas amostras de material vegetal submerso em um curso d'água. As amostras, constituídas por folhas, galhos e cascas em váriados estágios de decomposição, foram acondicionadas em sacos de papel Kraft (de ambiente terrestre) ou sacos pláticos (de ambiente aquático) e transportadas ao laboratório, onde foram submetidas à técnica de isolamento direto descrita por CastañedaRuiz (2005). Essa técnica consiste em lavar as amostras em água corrente por 30 min, incubá-las em câmarasúmidas a temperatura ambiente e, durante um período de 30 dias, examiná-las regularmente sob estereomicroscópio a procura de estruturas reprodutivas dos fungos conidiais. Lâminas permanentes foram confeccionadas transferindo-se as estruturas reprodutivas dos fungos conidiais para lâminas contendo resina PVL (álcool polivinílico + ácido lático + fenol). Lâminas e amostras vegetais secas foram depositadas no Herbário HUEFS (Universidade Estadual de Feira de Santana).

\section{Resultados e Discussão}

Foram identificadas 44 espécies de fungos conidiais associadas à decomposição da serapilheira. Destas, oito são novas ocorrências e são aqui descritas, ilustradas e comentadas. Uma lista com todas as espécies encontradas é também incluída.
Dendryphiosphaera parvula Nawawi \& Kuthub., Mycotaxon 32(1): 461.1988.

Fig. 1 a-c

Conidióforos macronemáticos, mononemáticos, retos ou levemente flexuosos, simples, eretos, 4-8 septados, lisos, castanhos na base, castanho-claros no ápice, $60-175 \times 5-6(-8) \mu \mathrm{m}$; células basais infladas, 10-12,5 $\mu \mathrm{m}$ larg. Células conidiogênicas monoblásticas ou poliblásticas, evidentes, subglobosas a ovóides, apicais ou laterais, arranjadas em verticilos no conidióforo, lisas, castanho-claras, (5-) 7-11 ×3-4 $\mu \mathrm{m}$. Conídios solitários, esquizolíticos, clavados, 1-euseptados na base, 1-distoseptados distalmente, septo basal mais espesso, simples, secos, lisos, castanho-claros, (9-) 10-12 (-14) $\times 4-5 \mu \mathrm{m}$.

Material examinado: BRASIL. BAHIA: Pindobaçu, Serra da Fumaça, sobre casca em decomposição, 11.IX.2008, D.A.C. Almeida s.n. (HUEFS154969).

Apenas quatro espécies foram descritas em Dendryphiosphaera: D. minuta V. Rao \& de Hoog, D. parvula Nawawi \& Kuthub., D. taiensis Lunghini \& Rambelli e D. uniseptata R.F. Castañeda \& Guarro (Rao \& Hoog 1986; Castañeda-Ruiz et al. 1998a; Nawawi \& Kuthubutheen 1988). Rao \& Hoog (1986) declararam não haver diferenças significativas entre os gêneros Dendryphiosphaera e Brachysporiella, mas optaram por não propor a sinonimização. Nawawi \& Kuthubutheen (1988), após examinarem diferentes isolados da Malásia de Brachysporiella gayana Bat., concluíram que as diferenças entre Dendryphiosphaera e Brachysporiella justificam a manutenção desses dois gêneros. Segundo estes últimos autores, Brachysporiella difere pelos conidióforos simples a ramificados e com até três ramificações, bem como pela proliferação percurrente dos conidióforos após a secessão conidial. Adicionalmente, os conídios das espécies de Brachysporiella são maiores, castanho-escuros e com parede espessa.

Dendryphiosphaera minuta e D. taiensis são as espécies mais similares à $D$. parvula . A primeira difere pelos conídios maiores e com dois septos verdadeiros; a segunda difere, principalmente, pelos conídios cilíndricos com septos verdadeiros equidistantes. A presença de um distosepto distal no conídio de $D$. parvula a distingue facilmente das demais espécies do gênero. As características do material brasileiro estão de acordo com a descrição de Nawawi \& Kuthubutheen (1988). Este é provalmente o segundo registro da espécie para o mundo e o primeiro para o continete americano. Encontrada na Malásia (Nawawi \& Kuthubutheen 1988). 

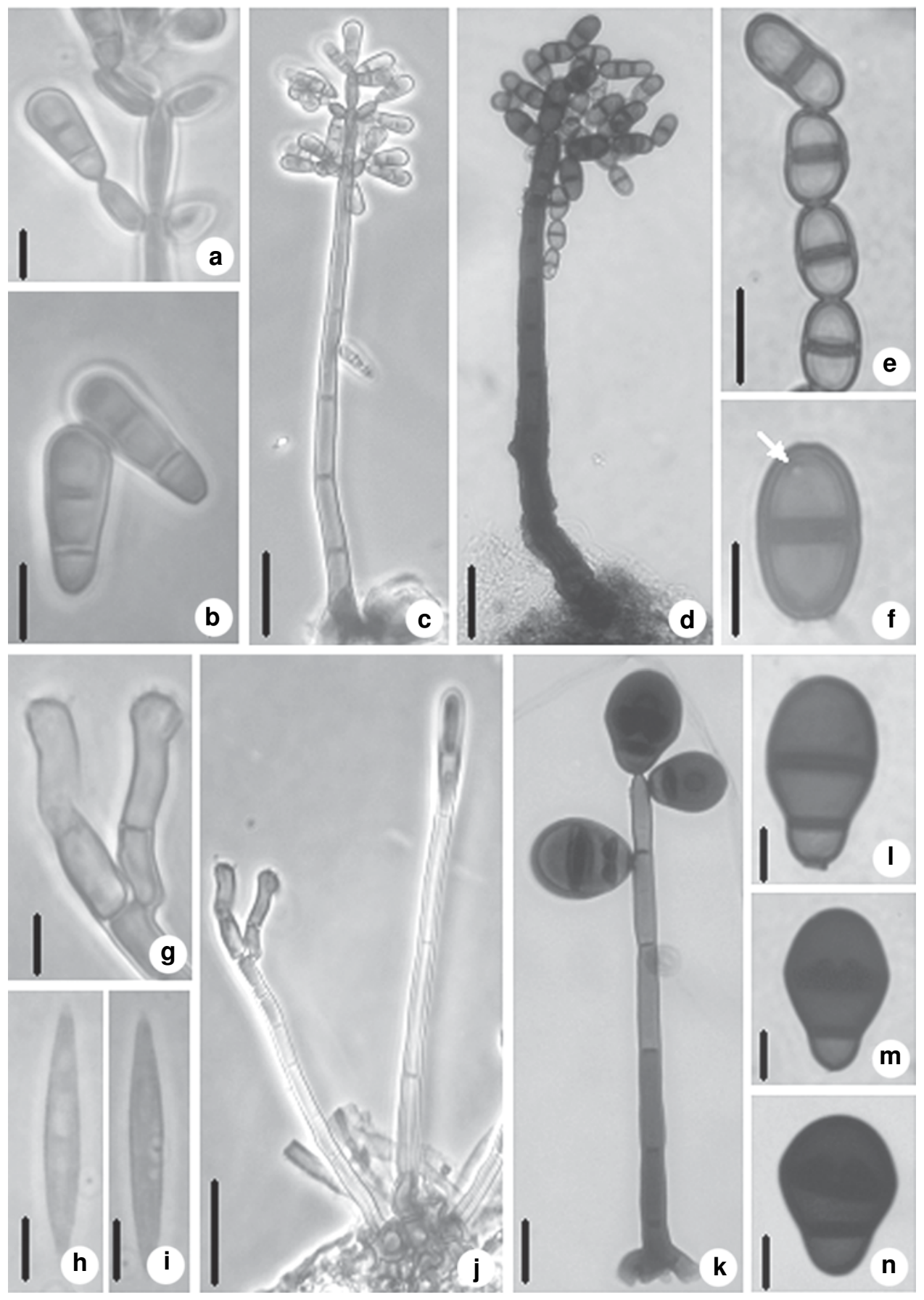

Figura 1 - a-c. Dendryphiosphaera parvula. Nawawi \& Kuthub. -a. ápice do conidióforo com células conidiogênicas e conídio; b. conídios; c. aspecto geral. d-f. Diplococcium dendrocalami Goh, K.D. Hyde \& Umali - d. aspecto geral; e. conídios em cadeia; f. conídio com poro em destaque (seta). g-j. Hemibeltrania decorosa R.F. Castañeda \& W.B. Kendr. - g. células conidiogênicas; h-i. conídios; j. conidióforo e seta. k-n. Spadicoides macroobovata Matsush. - k. aspecto geral; 1-n. Conídios. Barras: $20 \mu \mathrm{m}$ (c-d, j); $10 \mu \mathrm{m}$ (e, k); $5 \mu \mathrm{m}$ (b, a, f, g-i, 1-n).

Figure 1 - a-c. Dendryphiosphaera parvula Nawawi \& Kuthub. - a. apex of conidiophore with conidiogenous cells and conidium; b. conidia; c. general aspect. d-f. Diplococcium dendrocalam Goh, K.D. Hyde \& Umali - d. general aspect; e. chains of conidia; f. conidium with pore detail (arrow). g-j. Hemibeltrania decorosa R.F. Castañeda \& W.B. Kendr. - g. conidiogenous cells; h-i. conidia; j. conidiophore and seta. k-n. Spadicoides macroobovata Matsush. - k. general aspect; 1-n. conidia. Bars: $20 \mu \mathrm{m}$ (c-d, j); $10 \mu \mathrm{m}$ (e, k); $5 \mu \mathrm{m}$ (b, a, f, g-i, l-n). 
Diplococcium dendrocalami Goh, K.D. Hyde \& Umali, Mycologia 90(3):515. $1998 . \quad$ Fig. 1 d-f

Conidióforos macronemáticos, mononemáticos, retos ou flexuosos, septados, lisos, simples ou raramente ramificados, eretos, 1-2 regenerações percurrentes, cilíndricos, ápices arredondados, afilando levemente em direção ao ápice, castanhos, 92,5-167,5 × 8-12,5 $\mu \mathrm{m}$. Células conidiogênicas politréticas, terminais, integradas, determinadas, lisas, castanhas. Conídios em cadeias acrópetas, 1(-2) septados, septos medianos com $2 \mu \mathrm{m}$ de espessura, elípticos, secos, lisos, castanho-claros, $8-15 \times 5-7 \mu \mathrm{m}$. Material examinado: BRASIL. BAHIA: Pindobaçu, Serra da Fumaça, sobre folha em decomposição de dicotiledônea não identificada, 13.I.2009, DAC Almeida s.n. (HUEFS154970).

O gênero Diplococcium foi revisado por Goh \& Hyde (1998a), considerando 21 espécies, não incluindo entre elas $D$. atrovelutinum $\mathrm{U}$. Braun, Hosag. \& T.K. Abraham, proposta por Braun et al. (1996). Posteriormente foram adicionadas duas espécies: D. hughesii C.J.K. Wang \& B. Sutton (Wang \& Sutton 1998) e $D$. verruculosum A.C. Cruz, Gusmão \& R.F. Castañeda (Cruz et al. 2007b). Diplococcium dendrocalami é comparável à D. clavariarum (Desm.) Hol.-Jech. e D. insolitum Hol.-Jech. Diplococcium clavariarum diferencia-se por produzir conidióforos frequentemente ramificados e mais estreitos (3,5-6 $\mu \mathrm{m})$, bem como conídios mais extensos (14-29 $\mu \mathrm{m})$. Além disso, esta espécie foi relatada como parasita (Holubová-Jechová 1982), enquanto $D$. dendrocalami foi referida como sapróbia (Goh et al. 1998). Diplococcium insolitum distingue-se por produzir conídios comumente 2 -septados, obclavados, com célula basal castanha e célula apical hialina a subhialina (Holubová-Jechová 1982; Goh et al. 1998). O material examinado concorda com a descrição de Goh et al. (1998), exceto pela presença de raras ramificações nos conidióforos e conídios menores. Diplococcium dendrocalami é conhecida apenas da sua localidade-tipo. O material brasileiro representa o primeiro registro para o continente americano. Encontrada nas Filipinas (Goh et al. 1998).

Hemibeltrania decorosa R.F. Castañeda \& W.B. Kendr., Univ. Waterloo Biol. Ser. 35: 57.1991.

Fig. 1 g-j

Setas retas ou flexuosas, simples, eretas, ocasionalmente produzindo conídios no ápice, cilíndricas, lisas, capitadas, castanhas, 36-150×
3-6 $\mu \mathrm{m}$; células apicais infladas, clavadas, subhialinas, 4,5-7,5 $\mu \mathrm{m}$ larg. Conidióforos macronemáticos, mononemáticos, agrupados, retos a levemente flexuosos, simples ou ramificados, eretos, septados, lisos, célula basal lobada, castanhos, castanho-claros a subhialinos no ápice, 33-75 × 3-4,5 $\mu \mathrm{m}$. Células conidiogênicas poliblásticas, terminais, integradas, simpodiais, denticuladas, lisas, castanho-claras, 7,5-15×3-6 $\mu \mathrm{m}$. Dentículos inconspícuos. Conídios solitários, esquizolíticos, 0 -septados, naviculares a fusiformes, simples, secos, lisos, subhialinos, 18-22,5×3-4,5 $\mu \mathrm{m}$. Material examinado: BRASIL. BAHIA: Pindobaçu, Serra da Fumaça, sobre folha em decomposição de dicotiledônea não identificada, 16.IX.2008, DAC Almeida s.n. (HUEFS154972).

O gênero Hemibeltrania foi proposto por Pirozynski (1963) para acomodar duas espécies, Hansfordia cinnamomi Deighton e Mammaria nectandrae Bat. \& Maia e possui atualmente 10 espécies (Kirk 1983a, Castañeda-Ruiz \& Arnold 1985, Castañeda-Ruiz \& Kendrick 1991, Zucconi 1992, Matsushima 1996, Castañeda-Ruiz et al. 1998b, Shin \& Braun 1998, Fernandes et al. 2007). Gusmão \& Barbosa (2005) apresentaram uma chave para as nove espécies aceitas até àquela data. Hemibeltrania urbanodendrii Fernandes, Lustosa, R.W. Barreto \& J.L. Bezerra foi descrita recentemente por Fernandes et al. (2007). Hemibeltrania mitratae P. M. Kirk é sinônima de Dactylaria mitrata Matsush. e $H$. navicularis B. C. Sutton foi transferida para o gênero Subramaniomyces Varguese \& Rao (Castañeda-Ruiz et al. 1998b). A produção de setas é conhecida apenas em três espécies: H. cymbiformes Zucconi, H. decorosa e H. saikawae R.F. Castañeda, W.B. Kendr. \& Guarro. Hemibeltrania decorosa difere das demais espécies pela morfologia fusiforme a navicular do conídio, bem como pela largura maior dos conidióforos. O material examinado difere da descrição apresentada por Castañeda-Ruiz \& Kendrick (1991) pelos conídios um pouco mais largos, concordando nas demais características. Esta espécie está sendo referida pela primeira vez para a América do Sul. Encontrada em Cuba (Castañeda-Ruiz \& Kendrick 1991), Ilhas Maurício (Dulymamode et al. 2001).

Spadicoides macroobovata Matsush., Matsush. Mycol. Mem. 8: 36. 1995.

Fig. 1 k-n

Conidióforos macronemáticos, mononemáticos, retos, simples, eretos, septados, lisos, castanhos, 50$87,5 \times 4-5 \mu \mathrm{m}$. Células conidiogênicas produzindo conídos apicais de modo blástico e conídios laterais 
de modo trético, integradas, cilíndricas, lisas, castanhas. Conídios solitários, 2-septados, septos espessos, obovóides, simples, secos, lisos, células basais truncadas e castanhas, células distais castanho-escuras, 17,5-25×10-12,5 $\mu \mathrm{m}$.

Material examinado: BRASIL. BAHIA: Pindobaçu, Serra da Fumaça, sobre folha em decomposição de dicotiledônea não identificada, 17.XII.2008, D.A.C. Almeida s.n. (HUEFS154973).

O gênero Spadicoides foi estabelecido por Hughes (1958) com a espécie-tipo S. bina (Corda) S Hughes. Difere de Diplococcium basicamente pela produção de conídios solitários. Goh \& Hyde (1996) revisaram o gênero, considerando 21 espécies e apresentaram uma chave de identificação. Sete espécies foram posteriormente incluídas por Goh \& Hyde (1998b), Dulymamode et al. (1999), Zhou et al. (1999), Ho et al. (2002) e Cai et al. (2004). Spadicoides obovata (Cooke \& Ellis) S. Hughes é similar à $S$. macroobovata pela produção de conídios obvóides, 2-septados, septos espessos e com célula basal mais clara do que as demais, porém difere notavelmente pelo tamanho menor (Matsushima 1975; Ellis 1963). O espécime brasileiro apresentou conidióforos mais espessos, concordando nas demais características com a descrição original. Matsushima (1975) descreveu a produção de conídios apicais de modo blástico e de conídios laterais de modo trético. O material brasileiro, aparentemente, também produz conídios desses dois modos. O presente relato representa o segundo registro da espécie para o mundo e o primeiro para o Brasil. Encontrada no Peru (Matsushima 1995).

Sporidesmiella aspera Kuthub. \& Nawawi, Mycol. Res. 97(11): 1305. 1993.

Fig. 2 a-c

Setas presentes ou não; quando presentes retas, simples, eretas, septadas, verrucosas, afiladas em direção ao ápice, castanhas, 137,5-295 × 5-6 $\mu \mathrm{m}$. Conidióforos macronemáticos, mononemáticos, retos, simples, eretos, septados, verrucosos, castanhos na base, castanho-claros a subhialinos no ápice, 45-252×2,5-5 $\mu \mathrm{m}$. Células conidiogênicas poliblásticas, terminais, integradas, simpodiais e/ou percurrentes, cilíndricas, lisas, castanho-claras a subhialinas. Conídios solitários, 1-distoseptados, cilíndricos, simples, secos, lisos, base truncada, ápice arredondado, célula basal subhialina, célula distal castanho-clara, 15-22,8 $\times 3-5 \mu \mathrm{m}$.

Material examinado: BRASIL. BAHIA: Pindobaçu, Serra da Fumaça, sobre folha em decomposição de dicotiledônea não identificada, 11.IX.2008, D.A.C. Almeida s.n. (HUEFS154974); 19.XII.2008, D.A.C.
Almeida s.n. (HUEFS154975); sobre galho em decomposição, 28.XI.2008, D.A.C. Almeida s.n. (HUEFS154976).

O gênero Sporidesmiella foi estabelecido por Kirk (1982a) com a espécie-tipo $S$. claviformis P.M. Kirk e está constituído por 24 espécies e duas variedades (Yanna et al. 2001; Wu \& Zhuang 2005). Em dois, dos três espécimes coletados no presente trabalho, foi observada a presença de setas subuladas rugosas. Embora esta característica não tenha sido relatada na descrição original por Kuthubutheen \& Nawawi (1993), o material brasileiro é indistinguível de $S$. aspera em todas as demais características e, por isso, optou-se por identificar os espéciemes brasileiros nesta espécie. Observações desta natureza, onde os espécimes diferiam da descrição do holótipo apenas pela presença de uma seta, também foram relatadas por Kirk (1982b, 1983b) para S. parva (M.B. Ellis) P.M. Kirk e Anungitea fragilis B. Sutton. A ocorrência de verrucosidades no conidióforo é uma característica exclusiva de $S$. aspera e a distingue facilmente das demais espécies do gênero. Este é o primeiro registro da espécie para o continente americano. Encontrada na Malásia (Kuthubutheen \& Nawawi 1993).

Sporidesmiella fusiformis W.P. Wu, Fung. Divers. Res. Ser. 15: 228. 2005.

Fig. 2 d-g

Conidióforos macronemáticos, mononemáticos, retos ou flexuosos, 2-4 septados, lisos, simples, cilíndricos, castanhos, 55-105×7,5-10 $\mu \mathrm{m}$. Células conidiogênicas monoblásticas, terminais, integradas, 2-6 proliferações percurrentes, lisas, cilíndricas, castanhas. Conídios solitários, 12-20 distoseptados, simples, fusiformes, com porção basal alargada, secos, lisos, castanho-claros, 87,5-132,5 × (12,5-) 17,5-20(-27,5) $\mu \mathrm{m}$; ápices arredondados, 5-6 $\mu \mathrm{m}$ larg.; células basais cônicas, truncadas na base, $7-$ 7,5 $\mu \mathrm{m}$ larg.

Material examinado: BRASIL. BAHIA: Pindobaçu, Serra da Fumaça, sobre folha em decomposição de dicotiledônea não identificada, 25.VIII.2008, D.A.C. Almeida s.n. (HUEFS154977); 3.IX.2008, D.A.C. Almeida s.n. (HUEFS154978).

Sporidesmiella fusiformis W.P. Wu foi proposta por Wu \& Zhuang (2005) para um espécime isolado sobre ramos em decomposição na China. Conídios fusiformes são também produzidos por $S$. ciliaspora W.P. Wu e S. verruculosa W.P. Wu (Wu \& Zhuang 2005); contudo diferem pela presença de apêndices e de verrucosidades, respectivamente. Análise filogenética baseada em dados moleculares, realizada por Shenoy et al. (2006), indicou que S. fusiformis é relacionada a membros de Melanommataceae (Ascomycota). Exceto pelas medidas maiores dos 

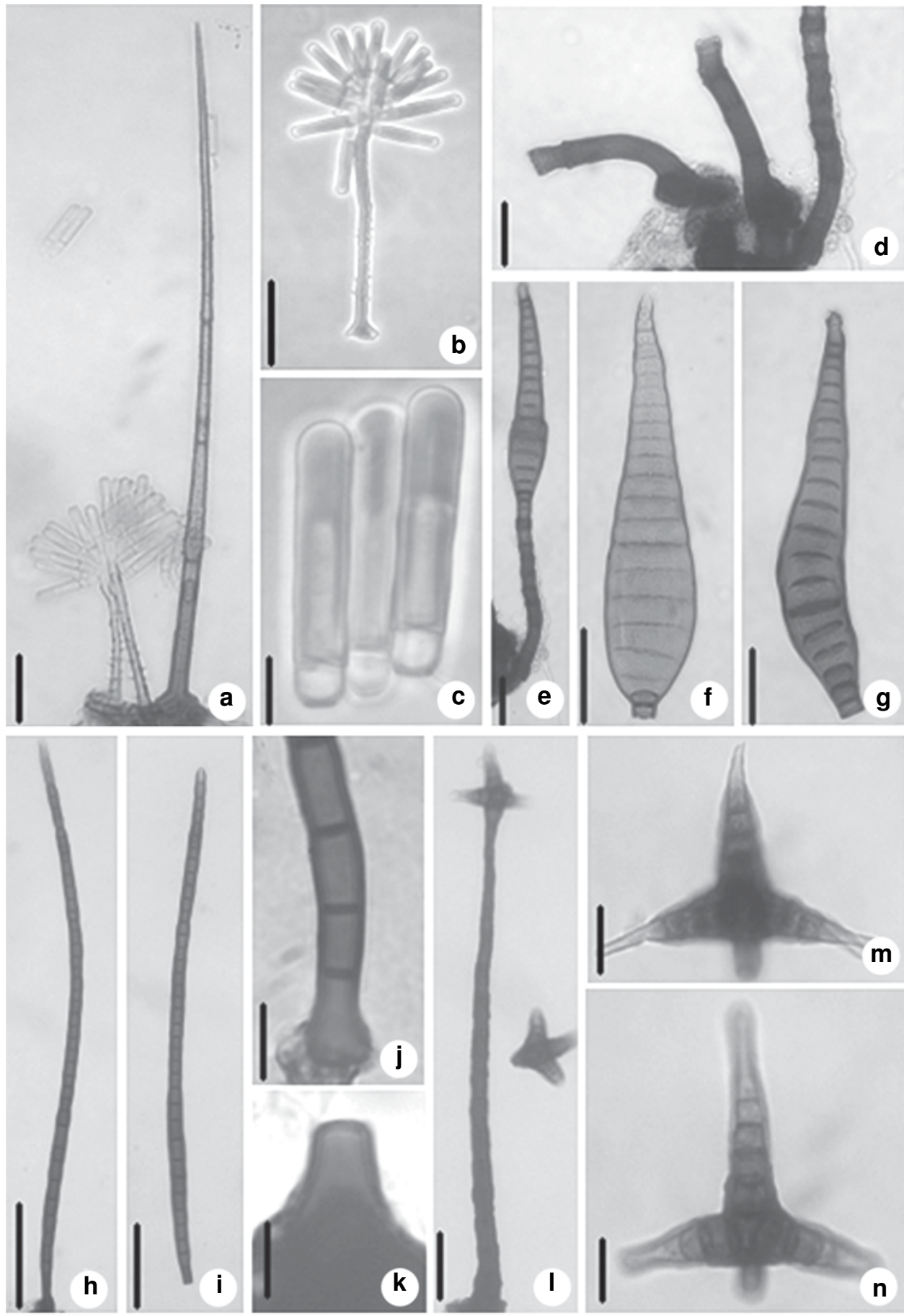

Figura 2 - a-c. Sporidesmiella aspera Kuthub. \& Nawawi - a. aspecto geral; b. conidióforo com conídios; c. conídios. d-g. Sporidesmiella fusiformis W.P. Wu - d. conidióforos com proliferação percurrente; e. aspecto geral; f-g. conídios. h-k. Stanjehughesia hormiscioides (Corda) Subram. - h. aspecto geral; i. conídio; j. célula conidiogênica e base do conídio; k. célula conidiogênica. 1-n. Triposporium verruculosum R.F. Castañeda, Gené \& Guarro - 1. aspecto geral; m-n. conídios. Barras: $50 \mu \mathrm{m}(\mathrm{h}-\mathrm{i}) ; 20 \mu \mathrm{m}$ (a-b, d-g, l); $10 \mu \mathrm{m}(\mathrm{j}, \mathrm{m}-\mathrm{n}) ; 5 \mu \mathrm{m}(\mathrm{c}, \mathrm{k})$.

Figure 2 - a-c. Sporidesmiella aspera Kuthub. \& Nawawi - a. general aspect; b. conidiophore with conidia; c. conidia. d-g. Sporidesmiella fusiformis W.P. Wu - d. conidiophores with percurrent proliferations; e. general aspect; f-g. conidia. h-k. Stanjehughesia hormiscioides (Corda) Subram. - h. general aspect; i. conidium; j. conidiogenous cell and base of conidium; k. conidiogenous cell. 1-n. Triposporium verruculosum R.F. Castañeda, Gené \& Guarro - 1. General aspect; m-n. Conidia. Bars: $50 \mu \mathrm{m}$ (h-i); $20 \mu \mathrm{m}$ (a-b, d-g, l); $10 \mu \mathrm{m}(\mathrm{j}, \mathrm{m}-\mathrm{n}) ; 5 \mu \mathrm{m}$ (c, k). 
conidióforos e dos conídios, o material brasileiro concordou com as demais características da espécie. O presente relato representa a primeira ocorrência de $S$. fusiformis para o continente americano. Encontrada na China (Wu \& Zhuang 2005).

Stanjehughesia hormiscioides (Corda) Subram., Proc. Indian natn Sci. Acad., Part B. Biol. Sci. 58(4): 184. 1992. Sporidesmium hormiscioides Corda, Icon. Fung. (Prague) 2: 6. 1838. Helmisporium hormiscioides (Corda) Sacc. Michelia 1: 85. 1877. Clasterosporium hormiscioides (Corda) Sacc., Syll. Fung. 4: 383. 1886. Clasterosporium vermiculatum Cooke, Grevillea 4: 69. 1875. Sporidesmium vermiculatum (Cooke) M.B. Ellis, Mycol. Pap. 70: 41. 1958. Stanjehughesia vermiculata (Cooke) Subram., Proc. Indian natn Sci. Acad., Part B. Biol. Sci. 58(4). 184. 1992. Fig. 2 h-k

Conidióforos ausentes. Células conidiogênicas, monoblásticas, determinadas, lageniformes, lisas, castanhas, 10-15 × 5-9 $\mu \mathrm{m}$. Conídios solitários, esquizolíticos, 20-42 septados, cilíndricos a fusiformes, retos ou flexuosos, simples, secos, lisos, castanhos, com ápice arredondado castanho-claro, 162,5-340×7,5-10 $\mu \mathrm{m}$; ápice 5-7,5 $\mu \mathrm{m}$ larg.; célula basal cônico-cilíndrica, truncada na base, 4-5 $\mu \mathrm{m}$ larg. Material examinado: BRASIL. BAHIA: Pindobaçu, Serra da Fumaça, sobre casca em decomposição de dicotiledônia não identificada, 22.XII.2008, D.A.C. Almeida s.n. (HUEFS154979).

Subramanian (1992) estabeleceu o gênero Stanjehughesia para acomodar cinco espécies previamente descritas em Sporidesmium Link., caracterizadas pelos conidióforos ausentes ou reduzidos às células conidiogênicas e pela produção de conídios solitários, acrógenos, secos, com septos verdadeiros. Este autor transferiu Sporidesmium vermiculatum e S. hormiscioides para Stanjehughesia mantendo-as como espécies distintas, discordando da sinonimização previamente proposta por Hughes (1958). Wu \& Zhuang (2005) adicionaram quatro espécies ao gênero e retiveram o nome específico Stanjehughesia vermiculata para um espécime coletado na China. Delgado (2008), entretanto, estudando o gênero, considerou Stanjehughesia. vermiculata $\mathrm{e}$. hormiscoides coespecíficas com base nas ilustrações de Ellis (1958, 1976). O presente trabalho segue as considerações de Delgado (2008) que mantém a sinonimização proposta por Hughes (1958). O material brasileiro apresentou conídios mais extensos e mais estreitos do que os relatados por Ellis (1958, 1976) e Wu \& Zhuang (2005). Este é o primeiro registro da espécie para o Neotrópico. Encontrada no Canadá, China (como Stanjehughesia vermiculata, Wu \& Zhuang 2005), Escócia e Inglaterra (Ellis 1958).

Triposporium verruculosum R.F. Castañeda, Gené \& Guarro, Mycotaxon 59: 207. $1996 . \quad$ Fig. 21 -n

Conidióforos macronemáticos, mononemáticos, retos ou flexuosos, simples, eretos, cilíndricos, rugosos em toda a extensão ou apenas na base, 8 18 septados, afilando em direção ao ápice, castanhoescuros na base, castanhos no ápice, 50-275 × 7,5$12,5 \mu \mathrm{m}$. Células conidiogênicas monoblásticas, terminais, integradas, determinadas, cilíndricas, lisas ou verrucosas, castanhas, 7,5-10 × 3-5 $\mu \mathrm{m}$. Conídios solitários, estrelados, secos, constituídos por uma região central com 2 células de onde originam-se 2-4 ramificações; ramificações retas, divergentes, subuladas, 3-6 septadas, verruculosas na base, lisas e arredondadas no ápice, castanhas na base, subhialinas no ápice, $12,5-37,5 \times 5-10 \mu \mathrm{m}$; ápice 2-5 $\mu \mathrm{m}$ larg.; células basais cônico-cilíndricas, truncadas, lisas, castanhas, 5-7,5 ×4-5 $\mu$ m; células supra-basais verrucosas, castanho-escuras, 7,5$10 \mu$ m diâm.

Material examinado: BRASIL. BAHIA: Pindobaçu, Serra da Fumaça, sobre folha em decomposição de dicotiledônia não identificada, 22.XII.2008, D.A.C. Almeida s.n. (HUEFS154980).

Triposporium verruculosum foi descrito por Castañeda-Ruiz et al. (1996), isolado sobre folhas em decomposição de Laurus sp. na Espanha. As espécies T. elegans Corda e T. lambdaseptatum (Matsush.) Kuthub. \& Nawawi (Kuthubutheen \& Nawawi 1991; Matsushima 1971) são semelhantes à $T$. verruculosum, mas podem ser diferenciadas pela ausência de verrucosidades na parede dos conídios e comprimento maior das ramificações (Ellis 1971; Castañeda-Ruiz et al. 1996). Os conídios de T. novoguineense Rifai (Rifai 1972) também são similares aos de $T$. verruculosum, contudo diferem pelas ramificações mais curtas e ausência de verrucosidades. As características do espécime examinado divergiram da descrição original pela ausência de proliferações percurrentes, menor tamanho das células conidiogênicas, das células basais e suprabasais dos conídios, bem como pelas ramificações dos conídios mais estreitas, no entanto, preferiu-se manter o espécime em $T$. verruculosum. O presente relato representa o primeiro registro da espécie para o continente americano. Encontrada na Espanha (Castañeda-Ruiz et al. 1996) e na Nova Zelândia (NZFUNGI 2009). 
Outras espécies de fungos conidiais encontradas no município de Pindobçu, Bahia:

Actinocladium rhodosporum Ehrenb., Jahrb. Gewächsk. 1(2): 52. 1819. Material examinado: (HUEFS154983).

Atrosetaphiale flagelliformis Matsush., Mycol. Mem. 8: 14. 1995. Material examinado: (HUEFS154985).

Beltrania rhombica Penz., Michelia 2(no. 8): 474. 1882. Material examinado: (HUEFS154989).

Beltraniella portoricensis (F. Stevens) Piroz. \& S.D. Patil, Can. J. Bot. 48(3): 575. 1970. Material examinado: (HUEFS155000).

Brachysporiella gayana Bat., Bol. Secr. Agric. (Pernambuco) 19(1-2): 109. 1952. Material examinado:(HUEFS155009).

Chaetopsina fulva Rambelli, Diagn. IV 3: 5. 1956. Material examinado: (HUEFS155010).

Chalara alabamensis Morgan-Jones \& E.G. Ingram, Mycotaxon 4(2): 489. 1976. Material examinado: (HUEFS155017).

Chalara cylindrosperma (Corda) S. Hughes, Can. J. Bot. 36: 747. 1958. Material examinado: (HUEFS155019).

Circinotrichum olivaceum (Speg.) Piroz., Mycol. Pap. 84: 6. 1962.Material examinado: (HUEFS155020).

Cladosporium oxysporum Berk. \& M.A. Curtis, Berkeley, J. Linn. Soc., Bot. 10(46): 362. 1868. Material examinado: (HUEFS155021).

Cladosporium cladosporioides (Fresen.) G.A. de Vries, Contrib. Knowledge of the Genus Cladosporium Link ex Fries: 57. 1952. Material examinado: (HUEFS155022).

Curvularia eragrostidis (Henn.) J.A. Mey., Publ. Inst. nat. Étude agron. Congo belge, Sér. sci. 75: 183. 1959. Material examinado: (HUEFS155023).

Cryptophiale kakombensis Piroz., Can. J. Bot. 46: 1124. 1968. Material examinado: (HUEFS155025).
Cryptophialoidea fasciculata Kuthub. \& Nawawi, Mycol. Res. 98(6): 686. 1994. Material examinado: (HUEFS155026).

Dictyochaeta anamorfo de Chaetosphaeria pulchriseta S. Hughes, W.B. Kendr. \& Shoemaker, N.Z. J1 Bot. 6: 356. 1968. Material examinado: (HUEFS155027).

Dictyochaetopsis polysetosa R.F. Castañeda, Gusmão, Guarro \& Saikawa, Mycotaxon, 103: 2. 2008. Material examinado: (HUEFS155028).

Ellisembia adscendens (Berk.) Subram., Proc. Indian natn Sci. Acad., Part B. Biol. Sci. 58(4): 183. 1992. Material examinado: (HUEFS155029).

Ellisembia leonensis (M.B. Ellis) McKenzie, Mycotaxon 56: 13. 1995. Material examinado: (HUEFS155032).

Endophragmiella boothii (M.B. Ellis) S. Hughes, N.Z. Jl Bot. 17(2): 147. 1979. Material examinado: (HUEFS155034).

Eversia parvula Hol.-Jech., Èeská Mykol. 41(1): 31. 1987. Material examinado: (HUEFS155035).

Exserticlava vasiformis (Matsush.) S. Hughes, N.Z. Jl Bot. 16(3): 332. 1978. Material examinado: (HUEFS155040).

Gonytrichum macrocladum (Sacc.) S. Hughes, Trans. Br. mycol. Soc. 34(4): 565. 1952. Material examinado: (HUEFS155042)

Gyrothrix podosperma var. podosperma (Corda) Rabenh., Deutschl. Krypt.-Fl. (Leipzig) 1: 72. 1844. Material examinado: (HUEFS155043).

Kionochaeta pughii Kuthub. \& Nawawi, Trans. Br. mycol. Soc. 90(3): 437. 1988. Material examinado: (HUEFS155046).

Kionochaeta ramifera (Matsush.) P.M. Kirk \& B. Sutton, Trans. Br. mycol. Soc. 85(4): 715. 1986. Material examinado: (HUEFS155047).

Menisporopsis novae-zelandiae S. Hughes \& W.B. Kendr., N.Z. J1 Bot. 6: 369. 1968. Material examinado: (HUEFS155049). 
Monotosporella setosa var. setosa (Berk. \& M.A. Curtis) S. Hughes, Can. J. Bot. 36: 787. 1958. Material examinado:(HUEFS155051).

Paliphora intermedia Alcorn, Mycotaxon 59: 145. 1996. Material examinado: (HUEFS155053).

Paraceratocladium silvestre R.F. Castañeda, Fungi Cubenses II (La Habana) 2: 9. 1987. Material examinado:(HUEFS155057).

Parasympodiella laxa (Subram. \& Vittal) Ponnappa, Trans. Br. mycol. Soc. 64(2): 344. 1975. Material examinado: (HUEFS155058).

Phaeoisaria infrafertilis B. Sutton \& Hodges, Nova Hedwigia 27(1-2): 219. 1976. Material examinado:(HUEFS155062).

Stachybotrys longispora Matsush., Icon. microfung. Matsush. lect. (Kobe): 145. 1975. Material examinado: (HUEFS155063),

Subulispora longirostrata Nawawi \& Kuthub., Mycotaxon 30: 459. 1987. Material examinado: (HUEFS155068).

Subulispora rectilineata Tubaki, in Tubaki \& Yokoyama, Trans. Mycol. Soc. Japan 12(1): 21. 1971. Material examinado: (HUEFS155070).

Vermiculariopsiella cubensis (R.F. Castañeda) Nawawi, Kuthub. \& B. Sutton, Mycotaxon 37: 180. 1990. Material examinado: (HUEFS155072).

Virgaria nigra (Link) Nees, Nat. Arr. Brit. Pl. (London) 1: 553. 1817. Material examinado: (HUEFS155073).

\section{Agradecimentos}

Os autores agradecem aos Drs. Gregorio Delgado, Roland Kirschner, Uwe Braun e Xiu-Guo Zhang a contribuição no envio de literatura. $\mathrm{O}$ primeiro autor agradece à Coordenação de Aperfeiçoamento de Pessoal de Nível Superior (CAPES) a bolsa concedida. L.F.P. Gusmão agradece ao CNPq (Proc. 474589/2008-0) o apoio financeiro.

\section{Referências}

Barbosa, F.R.; Gusmão, L.F.P. \& Barbosa, F.F. 2008. Fungos anamórficos (Hyphomycetes) no semi-árido do estado da Bahia, Brasil. Acta Botanica Brasilica 22: 29-36.
Barbosa, F.R.; Gusmão, L.F.P.; Castañeda-Ruiz, R.F.; Marques, M.F.O. \& Maia, L.C. 2007. Conidial fungi from the semi-arid Caatinga biome of Brazil. New species Deightoniella rugosa \& Diplocladiella cornitumida with new records for the neotropics. Mycotaxon 102: 39-49.

Barbosa, F.R.; Maia, L.C. \& Gusmão, L.F.P. 2009a. Fungos conidiais associados ao folhedo de Clusia melchiorii Gleason e C. nemorosa G. Mey. (Clusiaceae) em fragmento de Mata Atlântica, Bahia, Brasil. Acta Botanica Brasilica 23: 79-84.

Barbosa, F.R.; Maia, L.C. \& Gusmão, L.F.P. 2009 b. Novos registros de Hyphomycetes decompositores para o Estado da Bahia, Brasil. Acta Botanica Brasilica 23: 323-329.

Braun, U.; Hosagoudar, V.B. \& Abraham, T.K. 1996. Diplococcium atrovelutinum sp. nov. from India. New Botanist 23: 1-4.

Cai L.; McKenzie E.H.C. \& Hyde K.D. 2004. New species of Cordana and Spadicoides from decaying bamboo culms in China. Sydowia 56: 222-228.

Castañeda-Ruiz, R.F. 2005. Metodologia en el estudio de los hongos anamorfos. In: V Congresso Latino Americano de Micologia. Anais do V Congresso Latino Americano de Micologia. Brasília. Pp. 182-183.

Castañeda-Ruiz, R.F. \& Arnold, G.R.W. 1985. Deuteromycotina de Cuba. I. Hyphomycetes. Revista del Jardín Botánico Nacional 6: 47-67.

Castañeda-Ruiz, R.F.; Gené, J. \& Guarro, J. 1996. Litter hyphomycetes from la Gomera (Canaries). Mycotaxon 59: 203-215.

Castañeda-Ruiz, R.F.; Guarro, J.; Mayayo, E. \& Decock, C. 1998a. Notes on conidial fungi. XVI. A new species of Dendryphiosphaera and some new records from Cuba. Mycotaxon 67: 9-19.

Castañeda-Ruiz, R.F. \& Kendrick, W.B. 1991. Ninetynine conidial Fungi from Cuba and three from Canada. University of Waterloo, Biology Series 35: 1-132.

Castañeda-Ruiz, R.F.; Kendrick, B.; Guarro, J. \& Gené, J. 1998b. A new species of Hemibeltrania from Cuba. Mycological Research 102: 930-932.

Cruz, A.C.R. \& Gusmão, L.F.P. 2009a. Fungos conidiais na Caatinga: espécies associadas ao folhedo. Acta Botanica Brasilica 23: 999-1012.

Cruz, A.C.R. \& Gusmão, L.F.P. 2009b. Fungos conidiais na Caatinga: espécies lignícolas. Acta Botanica Brasilica 23: 1133-1144.

Cruz, A.C.R.; Gusmão, L.F.P. \& Castañeda-Ruiz, R.F. 2007a. Conidial fungi from the semi-arid Caatinga biome of Brazil. Subramaniomyces pulcher sp. nov. and notes on Sporidesmium circinophorum. Mycotaxon 102: 25-32.

Cruz, A.C.R.; Gusmão, L.F.P.; Leão-Ferreira, S.M. \& Castañeda-Ruiz, R.F. 2007b. Conidial fungi from the semi-arid Caatinga biome of Brazil. Diplococcium verruculosum sp. nov. and Lobatopedis longistriatum sp. nov. Mycotaxon 102: 33-38. 
Cruz, A.C.R.; Leão-Ferreira, S.M.; Barbosa, F.R. \& Gusmão, L.F.P. 2008. Conidial fungi from semiarid Caatinga biome of Brazil. New and interesting Dictyochaeta species. Mycotaxon 106: 15-27.

Cruz, A.C.R.; Marques, M.F.O. \& Gusmão, L.F.P. 2007c. Fungos anamórficos (Hyphomycetes) da Chapada Diamantina: novos registros para o Estado da Bahia e Brasil. Acta Botanica Brasilica 21: 847-855.

Delgado, G. 2008. South Florida microfungi: a new species of Stanjehughesia (hyphomycetes) from Sabal palm. Mycotaxon 103: 229-234.

Dulymamode, R.; Cannon, P.F. \& Peerally, A. 2001. Fungi on endemic plants of Mauritius. Mycological Research 105: 1472-1479.

Dulymamode, R.; Kirk, P. M. \& Peerally, A. 1999. Fungi from Mauritius: three new hyphomycetes species on endemic plants. Mycotaxon 73: 313-323.

Ellis, M.B. 1958. Clasterosporium and some allied Dematiaceae - Phragmosporae. I. Mycological Papers 70: 1-89.

Ellis, M.B. 1963. Dematiaceous hyphomycetes. V. Mycological Papers 93: 1-33.

Ellis, M.B. 1971. Dematiaceous hyphomycetes. Commonwealth Mycological Institute, Kew. 608p.

Ellis M.B. 1976. More dematiaceous hyphomycetes. Commonwealth Mycological Institute, Kew. 507p.

Fernandes, R.C.; Lustosa, D.C.; Barreto, R.W.\& Bezerra, J.L. 2007. Hemibeltrania urbanodendrii sp. nov. and Peudobeltrania angamosensis: new fungal records from the Brazilian Tropical Seasonal SemiDeciduous Montane Forest. Brazilian Journal of Microbiology 38: 756-758.

Goh, T.K. \& Hyde, K.D. 1996. Spadicoides cordanoides sp. nov., a new dematiaceous hyphomycete from submerged wood in Australia, with a taxonomic review of the genus. Mycologia 88: 1022-1031.

Goh, T.K \& Hyde, K.D. 1998a. A synopsis of and a key to Diplococcium species, based on the literature, with a description of a new species. Fungal Diversity 1: $65-83$

Goh, T.K \& Hyde, K.D. 1998b. Spadicoides palmicola sp. nov. on Licuala sp. from Brunei, and a note on Spadicoides heterocolorata comb. nov. Canadian Journal of Botany 76: 1698-1702.

Goh, T.K.; Hyde, K.D. \& Umali, T.E. 1998. Two new species of Diplococcium from the Tropics. Mycologia 90: 514-517.

Gusmão, L.F.P. \& Barbosa, F.R. 2005. Hemibeltrania (anamorphic fungi - Hyphomycetes) from the state of Bahia, Brazil. Sitientibus: Série Ciências Biológicas 5: 17-19.

Gusmão, L.F.P.; Barbosa, F.R. \& Barbosa, F.F. 2006. Fungos conidiais. In: Gusmão, L.F.P. \& Maia, L.C. (orgs.). Diversidade e caracterização dos fungos no semi-árido. 1ed. Associação Plantas do Nordeste, Recife. Pp. 27-47.
Gusmão, L.F.P.; Barbosa, F.R. \& Cruz, A.C.R. 2005. Espécies de Curvularia (Fungos anamórficos - hyphomycetes) no semi-árido do estado da Bahia, Brasil. Sitientibus: Série Ciências Biológicas 5: 12-16.

Gusmão, L.F.P.; Leão-Ferreira, S.M.; Marques, M.F.O. \& Almeida, D.A.C. 2008a. New species and records of Paliphora from the Brazilian semi-arid region. Mycologia 100: 306-309.

Gusmão, L.F.P.; Marques, M.F.O.; Cruz, A.C.R. \& Barbosa, F.R. 2008b. Diversidade dos fungos conidiais na região semi-árida do Brasil: situação atual e perspectivas. In: Heredia, G. (ed.). Tópicos sobre diversidad, ecología, y uso de los hongos microscópicos en Iberoamérica. Programa Iberoamericano de Ciencia y Tecnología para el Desarrollo (CYTED) e Instituto de Ecología, A.C. Xalapa, Ver. México. Pp. 43-61.

Ho, W.H.; Yanna \& Hyde, K.D. 2002. Two new species of Spadicoides from Brunei and Hong Kong. Mycologia 94: 302-306.

Holubová-Jechová, V. 1982. Lignicolous Hyphomycetes from Czechoslovakia 6. Spadicoides and Diplococcium. Folia Geobotanica \& Phytotaxonomica 17: 295-327.

Hughes, S.J. 1958. Revisiones hyphomycetum aliquot cum appendice de nominibus rejiciendis. Canadian Journal of Botany 36: 727-836.

Kirk, P.M. 1982a. New or interesting microfungi VI. Sporidesmiella gen. nov. (hyphomycetes). Transactions of the British Mycology Society 79: 479-489.

Kirk, P.M. 1982b. New or interesting Microfungi. IV. Dematiaceous hyphomycetes from Devon. Transactions of the British Mycology Society 78: 55-74.

Kirk, P.M. 1983a. New or interesting microfungi IX. Dematiaceous hyphomycetes from Esher Common. Transactions of the British Mycological Society 80: 449-467.

Kirk, P.M. 1983b. New or interesting microfungi X. Hyphomycetes on Laurus nobilis leaf litter. Mycotaxon 18: 259-298.

Kuthubutheen, A.J. \& Nawawi, A. 1991. A new species of Ceratosporella and Triposporium lambdaseptatum (Matsush.) comb. nov. from Malaysia. Mycological Research 95: 158-162.

Kuthubutheen, A.J. \& Nawawi, A. 1993. Three new and several interesting species of Sporidesmiella from submerged litter in Malaysia. Mycological Research 97: 1305-1314.

Leal, I.R.; Tabarelli, M. \& Silva, J.M.C. 2003. Introdução. In: Leal, I.R.; Tabarelli, M. \& Silva, J.M.C. (eds.). Ecologia e conservação da caatinga. Ed. Universitária, Universidade Federal de Pernambuco, Recife. Pp. 13-17.

Marques, M.F.O.; Barbosa, F.R.; Gusmão, L.F.P.; Catañeda Ruiz, R.F. \& Maia, L.C. 2007. Conidial fungi from the semi-arid caatinga biome of Brazil. Cubasina microspora sp. nov., a note on $C$. albofusca, and some new records for South America. Mycotaxon 102: 17-23. 
Marques, M.F.O.; Gusmão, L.F.P. \& Maia, L.C. 2008. Espécies de Vermiculariopsiella (Hyphomycetes) associadas a substratos vegetais em fragmento de Mata Atlântica, Serra da Jibóia, estado da Bahia, Brasil. Revista Brasileira de Botânica 31: 659-665.

Mascarenhas, J.F.; Ledru, P.; Souza, S.L.; Conceição Filho, V.M.; Melo, L.F.A.; Lorenzo, C.L. \& Milési, J.P. 1998. Geologia e recursos minerais do Grupo Jacobina e da parte sul do Greenstone Belt de Mundo Novo. Série Arquivos Abertos. Companhia Baiana de Pesquisa Mineral, Salvador. 58p.

Matsushima, T. 1971. Microfungi of the Solomon Islands and Papua-New Guinea. Published by the author, Kobe. 78p.

Matsushima, T. 1975. Icones Microfungorum a Matsushima Lectorum. Published by the author, Kobe. 209p.

Matsushima, T. 1995. Matsushima Mycological Memoirs n. 8. Published by the author, Kobe, 60p.

Matsushima, T. 1996. Matsushima Mycological Memoirs n 9. Published by the author, Kobe. 30p.

Milesi, J.P.; Ledru, P.; Marcoux, E.; Mougeot, R.; Johan, V.; Lerouge, C.; Sabate, P.; Bailly, L.; Respaut, J.P. \& Skipwith, P. 2002. The Jacobina Paleoproterozoic gold-bearing conglomerates, Bahia, Brazil: a "hydrothermal shear-reservoir' model. Ore Geology Reviews 19: 95-136.

Ministério da Integração Nacional. 2005. Secretaria de políticas de desenvolvimento regional. Nova delimitação do semi-árido brasileiro. Brasília: MISDR.

Nawawi, A. \& Kuthubutheen, A.J. 1988. A new species of the genus Dendryphiosphaera. Mycotaxon 32: 461-466.

NZFUNGI - New Zealand Fungi (and Bacteria). Provide a gateway to a wealth of information on fungi (and plant pathogenic bacteria) in New Zealand. Disponível em $<$ http://nzfungi.landcareresearch.co.nz > Acesso em 18 agosto 2009.

Pirozynski, K.A. 1963. Beltrania and related genera. Mycological Papers 90: 1-37.

Prado, D.E. 2003. As caatingas da América do Sul. In: Leal, I.R.; Tabarelli, M. \& Silva, J.M.C. (eds.).
Ecologia e conservação da caatinga. Ed. Universitária, Universidade Federal de Pernambuco, Recife. Pp. 3-73.

Rao, V. \& Hoog, G.S. 1986. New or critical hyphomycetes from India. Studies in Mycology 28: 1-84.

Rifai, M.A. 1972. A new tropical species of Triposporium. Reinwardtia 8: 365-367.

Sampaio, E.V.S.B.; Giulietti, A.M.; Virgínio, J. \& Gamarra-Rojas, C.F.L. 2002. Vegetação e flora da caatinga. Associação Plantas do Nordeste, APNE/ CNIP, Recife. 176p.

Shenoy, B.D.; Jeewon, R.; Wu, W.P.; Bhat, D.J. \& Hyde, K.D. 2006. Ribosomal and RPB2 DNA sequence analyses suggest that Sporidesmium and morphologically similar genera are polyphyletic. Mycological Research 110: 916-928.

Shin, H.-D. \& Braun, U. 1998. A new species of Hemibeltrania on Convallaria keiskei. Mycotaxon 67: 317-321.

Subramanian C.V. 1992. A reassessment of Sporidesmium (hyphomycetes) and some related taxa. Proceedings of the Indian National Science Academy 58: 179-190.

Wang, C.J.K. \& Sutton, B.C. 1998. Diplococcium hughesii sp. nov. with a Selenosporella synanamorph. Canadian Journal of Botany 76: 1608-1613.

Wu, W. \& Zhuang, W. 2005. Sporidesmium, Endophragmiella and related genera from China. Fungal Diversity Research Series 15. Fungal Diversity Press, Hong Kong. 531p.

Yanna; Ho, W.H.; Hyde, K.D. \& McKenzie, E.H.C. 2001. Sporidesmiella oraniopsis, a new species of dematiaceous hyphomycete from North Queensland, Australia and synopsis of the genus. Fungal Diversity 8: 183-190.

Zhou, D.Q.; Goh, T.K.; Hyde, K.D. \& Vrijmoed, L.L.P. 1999. A new species of Spadicoides and other hyphomycetes on bamboo from Hong Kong. Fungal Diversity 3: 179-185.

Zucconi, L. 1992. Hemibeltrania cymbiformis sp. nov., a new Hyphomycetes from Ivory Coast forest litter. Mycological Research 96: 154-156. 